\title{
A contemporary approach to body mass regulation mechanisms
}

\author{
Andrzej Nowak, Elżbieta Czkwianianc \\ Department of Gastroenterology, Allergology and Pediatrics, Polish Mother's Memorial Hospital Research Institute, Lodz, Poland
}

Gastroenterology Rev 2016; 11 (2): 73-77

DOI: $10.5114 / p g .2016 .60043$

Key words: ghrelin, orexigenic factors, neuropeptide Y.

Address for correspondence: Andrzej Nowak MD, PhD, Department of Gastroenterology, Allergology and Pediatrics, Polish Mother's Memorial Hospital Research Institute, 281/289 Rzgowska St, 93-338 Lodz, Poland, e-mail: andrzejn1984@gmail.com

\begin{abstract}
Recently, a lot of factors and mechanisms regulating body mass have been discovered, although there are still many unknowns. Their effect on the development of many diseases related to nutritional disorders (obesity, anorexia, celiac disease, inflammatory bowel disease) means that the understanding of these mechanisms will make it possible to determine new therapeutic goals and create new medicinal products. This is even more important because nowadays there is no effective medication to cure nutritional disorders. It is necessary to conduct further research to evaluate dependencies and relationships between particular hormones and to study newly discovered substances so that we could progress towards achieving the overall objectives while keeping the ultimate goals in mind.
\end{abstract}

\section{Introduction}

The regulation of body mass is a complex process affected by metabolic and hormonal determinants, genetic predispositions, as well as behavioural, cultural, and environmental factors. A simplified definition of body mass sets forth a linear relationship between food intake and energy expenditure having an impact on the amount of stored fatty tissue [1] although it fails to reflect in full the multi-factor complexity of this process.

At present, nutrition disorders occur in approximately $40-50 \%$ of the worldwide population and they pose a significant health and social problem. In the light of these data the understanding of physiological processes regulating body mass takes on a new meaning. Only a comprehensive explanation of this complex process, the dependencies, and disorders leading to the development of diseases will make it possible to determine new therapeutic options. The aim of this article is to resume the present status of knowledge about the regulation of body mass.

An elementary centre coordinating and integrating central and peripheral signals regarding the current nutritional status and the levels of energy resources is the arcuate nucleus [2, 3]. This nucleus is located in the mediobasal hypothalamus, adjacent to the third cere- bral ventricle where the blood-brain barrier is semipermeable [4], thus making it possible to sense peripheral signals. It contains two types of cells:

- Orexigenic cells demonstrating the co-expression of neuropeptide $Y$ (NPY) and Agouti-related protein (AgRP); the activation of these cells stimulates food intake $[5,6]$;

- Anorexigenic cells demonstrating the co-expression of proopiomelanocortin (POMC) and cocaine-and amphetamine-regulated transcript (CART); the activation of these cells results in the occurrence of a sensation of satiety and inhibits food intake [7, 8].

The arcuate nucleus is the place where the hunger or satiety signal is communicated through transmitters characteristic of this site to other parts of the hypothalamus, such as the paraventricular nucleus and lateral hypothalamic area, as well as further to the peripheral nervous system and the endocrine system [9].

\section{Orexigenic factors that are where the sensation of hunger originates}

The main factors stimulating orexigenic neurons of the arcuate nucleus include [10]: hypoglycaemia, ghrelin, cortisol. 
According to contemporary studies, ghrelin appears to be the most important determinant in this group as the direct peripheral factor initiating food intake [1]. Ghrelin is a protein hormone produced by mucosal cells in the gastric fundus and secreted upon hunger. In the hour after consumingg a meal its level in blood becomes normalised, and this quality makes ghrelin a good marker of the actual nutritional status [10]. Permeating through the blood-brain barrier, orexigenic neurons of the arcuate nucleus induce the release of neuropeptide $Y$ and Agouti-related protein.

Neuropeptide $Y$ is the factor with the greatest orexigenic potential in the human body; it stimulates intake of a meal rich in carbohydrates, even under satiety, boosts motivation to eat, delays the occurrence of satiety, and, accordingly, increases the volume of a meal [9]. Mice with damaged NPY/AgRP neurons were incapable of developing the condition of hyperphagia in response to a negative energy balance and thereby of maintaining the correct body mass [11]. The activity of neuropeptide $\mathrm{Y}$ is fast but short-term whereas Agouti protein, which also increases the amount of calories intake, has a long-term effect. The latter one works by inhibiting the activity of the melanocortin system [12] (this system is described further in this article).

Other factors demonstrating a potential orexigenic effect are as follows:

- Enkephalin (ENK) and galanin (GAL) - neurotransmitters expressed in the paraventricular nucleus (PVN) $[13,14]$;

- Orexin-A and orexin-B synthesised in the lateral hypothalamus, especially orexin-A [15], which is stimulated under starvation and hypoglycaemia;

- RF-amide peptide synthesised in the paraventricular and lateral hypothalamic nuclei.

In addition to the hypothalamus, the brainstem also has an effect on food intake. Acting through the nucleus of the solitary tract it controls the autonomous regulation of eating behaviours, which determine the volume of a meal; however, they are insufficient to induce a response to starvation or a negative energy balance, which is actually the function triggered by the hypothalamus.

Eating is not only a reflex reaction, but also a reaction aimed at maintaining energy homeostasis. It is also and sometimes only a sheer pleasure. However, biological processes control the sensation of pleasure. Ghrelin engages the mesolimbic pathway (the reward system [16]); its secretion to the ventral tegmental area (VTA) and the nucleus accumbens septi (NAc) causes a dopamine release and food intake [17]. Orexin has a similar effect. The VTA stimulation increases appetite irrespective of energy demand - this action prevails over other hormonal signals. Leptin and insulin have an inhibitory effect on that system. Insulin increases the number of dopamine D2 receptors, accelerating the removal of dopamine, and thereby it shortens the response of the reward system and reduces eating-related pleasure. The hedonic aspect of having a meal (eating sweets and tasty food) is also mediated by the endocannabinoid system - its action is independent of neuropeptide $Y$. Although endocannabinoid receptors are present on the arcuate and paraventricular nuclei, it seems that the main point of interception of the cannabinoid system is the mesolimbic pathway. Endocannabinoids increase dopamine energy transmission in that pathway. Elevation of the concentration of endocannabinoids is also affected by ghrelin, which increases their concentration in the hypothalamus [18], and by leptin, which has the opposite effect [19]. The contribution of endocannabinoids in the regulation of energy homeostasis is not only limited to their effect on the central nervous system - they also stimulate lipogenesis and the build-up of adipose tissue, and they also have an impact on the utilisation of energy by inhibiting the thermogenesis process [20].

\section{Anorexigenic factors that are where the sensation of satiety originates}

The best-known anorexigenic factor is leptin. This is a hormone produced by adipocytes in proportion to the amount of adipose tissue. Leptin activates anorexigenic POMC/CART neurons while causing a release of $\alpha-M S H$ and cocaine- and amphetamine-regulated transcript derived from proopiomelanocortin. The released neuropeptides interact with melanocortin receptors, types 3 , and 4 (MC3R and MC4R) in the ventromedial nucleus. The stimulation of these receptors releases the sensation of satiety and inhibits food intake.

In addition, leptin inhibits the activity of orexigenic neurons in the arcuate nucleus, both through decreasing gene expression for neuropeptide $Y$ and Agouti-related protein [21], and through hyperpolarisation of these neurons.

The other peripheral signal, in addition to leptin, on the so-called long-term axis of food intake regulation is insulin. It also inhibits release of neuropeptide $Y$ and activates anorexigenic neurons of the arcuate nucleus. Furthermore, insulin stimulates release of leptin from adipocytes, and it has an effect on a reduction of ghrelin levels regardless of blood glucose concentration [22].

A determinant of the volume of a meal is primarily the time when the meal is finished. Satiety signals emitted directly by the alimentary tract play a decisive part in this process. Some proteins that are known to have potentially such properties are as follows:

- Cholecystokinin (CCK), a protein, which is secreted as a result of having a meal, especially with high protein 
content, in duodenal and jejunal mucosal cells, stimulates CCK-1 receptors located on afferent fibres of the vagus nerve. This protein has a very short half-life (only $2 \mathrm{~min}$ ), and therefore it also has a short-term effect as an appetite modulator. It causes a reduction in the volume of a given meal; however, it has no effect on the daily caloric supply because the frequency of meals is increased to compensate for that reduction. Furthermore, it delays gastric emptying, stimulates small intestine motility, and inhibits large intestine motility [23].

- Peptide $Y Y$ - it is synthesised in the small intestine, colon, and rectum in response to food intake, but an increase in its concentration occurs within just 15 min after a meal, and therefore it is not probable that it is synthesised as a result of the stimulation of receptors in the alimentary tract by a meal; its action is mediated in another way that is still unknown. Peptide YY reduces NPY and AgRP expression in the hypothalamus, concurrently activating POMC/CART neurons, and it suppresses postprandial ghrelin levels and inhibits intestinal motility [17].

- Pancreatic polypeptide (PP) is a polypeptide secreted by pancreatic cells in response to food intake. Its secretion is increased in proportion to the caloric value of a consumed meal. While being released peripherally, it suppresses appetite and causes a decrease in the amount of consumed calories [23].

- Glucagon-like peptide-1 (GLP-1) and oxyntomodulin are the products derived from the posttranslational processing of the proglucagon gene in the brain, intestines, and pancreas. The proteins are released in response to fatty acids and carbohydrates in the lumen of the small intestine in proportion to the amount of consumed calories. They have a short half-life. Oxyntomodulin increases energy expenditure and reduces ghrelin concentration levels. Glucagon-like peptide-1 inhibits gastric emptying, stimulates insulin release, suppresses the secretion of glucagon, and restrains appetite [23].

- Amylin is co-secreted with insulin from the pancreatic islet $\beta$-cells as the result of food intake. It inhibits the secretion of glucagon, delays gastric emptying, and thus reduces the volume of a consumed meal [24].

- Exendin 4 is glucagon-like peptide-1 receptor agonist; it promotes insulin release, decreases the volume of a meal, and improves the sensitivity tissues on insulin [25].

- Xenin is produced by endocrine cells of the gastric cardia, duodenum and small intestine in response to a meal; it reduces daily food intake and shortens the duration of a meal [26].

Moreover, the substances having an anorexigenic effect also include proteins secreted from adipose tis- sue, with leptin, already mentioned in this article, as the most important hormone.

- Adiponectin increases sensitivity to insulin and enhances glucose expenditure and lipid oxidation, thereby leading to a decrease in the concentration of free fatty acids and triglyceride content in the liver and skeletal muscles [27].

- Vaspin belongs to the group of serine protease inhibitors. The peripheral and central vaspin administration reduces food intake in animals. Vaspin expression has been proven in tissues that are involved in the regulation of food intake (gastric mucosal cells, liver, pancreas, hypothalamus) $[28,29]$.

- Nesfatin-1 is a peptide expressed in the central nervous system and peripheral tissues such as adipose tissue and alimentary tract. It has an inhibitory effect on hunger; its function in maintaining energy homeostasis has not been determined yet [30].

Some of the aforementioned factors affecting the hypothalamus have also an impact on the autonomous nervous system. For instance, ghrelin receptors are present on the vagus neurons; their stimulation results in reduced parasympathetic activity, while a decrease in leptin concentration results in an increase of vagal nerve tone.

Table I. The effect of the most important factors described herein on metabolism and adipogenesis

Ghrelin:
- Stimulates adipogenesis, increases expression of enzymes
responsible for storage of adipose tissue
- Decreases the utilisation of adipose tissue as an energy
source
- Reduces oxygen consumption
- Reduces expression of thermogenesis-related proteins
in brown adipose tissue
- Stimulates gastric emptying and intestinal motility
- Stimulates gastric secretion of hydrochloric acid
- Inhibits insulin secretion while causing an increase in blood
glucose concentration; it also increases insulin sensitivity
of tissues, and therefore it is considered to be a diabetogenic
factor
Neuropeptide Y:
- Stimulates lipogenesis
- Inhibits the action of the sympathetic system
- Inhibits thermogenesis in brown adipose tissue
- Inhibits the secretion of gonadoliberin and LH; reduces
the sex drive
- Lowers body temperature
- Inhibits the secretion of the growth hormone
- - Activates the sympathetic system
- Activates lipolysis; inhibits lipogenesis
- Stimulates the secretion of growth hormone, catecholamines,
and thyroid hormones, leading to the stimulation of
-


Furthermore, the regulation of body mass is affected by the factors having an impact on metabolism and adipogenesis as well as adipolysis, thus making this very intricate system of dependencies even more complex. The description of all these factors is beyond the scope of this paper. The effect of the most important factors described herein on metabolism and adipogenesis has been shown in the Table I.

Recently, a lot of factors and mechanisms regulating body mass have been discovered, although there are still many unknowns. Their effect on the development of many diseases related to nutritional disorders (obesity, anorexia, celiac disease, inflammatory bowel disease) means that the understanding of these mechanisms will make it possible to determine new therapeutic goals and create new medicinal products. This is even more important because nowadays there is no effective medication to cure nutritional disorders. It is necessary to conduct further research to evaluate dependencies and relationships between particular hormones and to study newly discovered substances so that we can progress towards achieving the overall objectives while keeping the ultimate goals in mind.

\section{Conflict of interest}

The authors declare no conflict of interest.

\section{References}

1. Nogueiras R, Tschöp M, Zigman J. CNS regulation of energy metabolism: ghrelin versus leptin. Ann N Y Acad D Sci 2008; 1126: 14-9.

2. Cone RD, Cowley MA, Butler AA, et al. The arcuate nucleus as a conduit for diverse signals relevant to energy homeostasis. Int J Obes Relat Metab Disord 2001; 25 Suppl. 5: S63-7.

3. Cowley MA, Smith RG, Diano S, et al. The distribution and mechanism of action of ghrelin in the CNS demonstrates a novel hypothalamic circuit regulating energy homeostasis. Neuron 2003; 37: 649-61.

4. Broadwell RD, Brightman MW. Entry of peroxidase into neurons of the central and peripheral nervous systems from extracerebral and cerebral blood. J Comp Neurol 1976; 166: 257-83.

5. Hahn TM, Breininger JF, Baskin DG, Schwartz MW. Coexpression of Agrp and NPY in fasting-activated hypothalamic neurons. Nat Neurosci 1998; 1: 271-2.

6. Shutter JR, Graham M, Kinsey AC, et al. Hypothalamic expression of ART, a novel gene related to agouti, is up-regulated in obese and diabetic mutant mice. Genes Dev 1997; 11: 593-602.

7. Elias CF, Lee C, Kelly J, et al. Leptin activates hypothalamic CART neurons projecting to the spinal cord. Neuron 1998; 21: 1375-85.

8. Kristensen P, Judge ME, Thim L, et al. Hypothalamic CART is a new anorectic peptide regulated by leptin. Nature 1998; 393: 72-6.
9. Minor RK, Chang JW, de Cabo R. Hungry for life: how the arcuate nucleus and neuropeptide $Y$ may play a critical role in mediating the benefits of calorie restriction. Mol Cell Endocrinol 2009; 299: 79-88.

10. Cummings D, Purnell J, Frayo R, et al. A preprandial rise in plasma ghrelin levels suggests a role in meal initiation in humans. Diabetes 2001; 50: 1714-9.

11. Qian S, Chen H, Weingarth D, et al. Neither agouti-related protein nor neuropeptide $\mathrm{Y}$ is critically required for the regulation of energy homeostasis in mice. Mol Cell Biol 2002; 22: 5027-35.

12. Morton GJ, Cummings DE, Baskin DG, et al. Central nervous system control of food intake and body weight. Nature 2006; 443: 289-95.

13. Chang GQ, Karatayev O, Ahsan R, et al. Dietary fat stimulates endogenous enkephalin and dynorphin in the paraventricular nucleus: role of circulating triglycerides. Am J Physiol Endocrinol Metab 2007; 292: E561-70.

14. Cisowska A, Ciosek J. Galanina - biosynteza, receptory i kierunki działania. Endokrynol Pol 2003; 6: 776-83.

15. Jawiarczyk A, Bolanowski M. Oreksyny - neuropeptydy o działaniu plejotropowym. Endokrynol Otyłość i Zaburzenia Przemiany Materii 2010; 6: 147-53.

16. Lockie SH, Dinan T, Lawrence AJ, et al. Diet-induced obesity causes ghrelin resistance in reward processing tasks. Psychoneuroendocrinology 2015; 62: 114-20.

17. Batterham RL, Cowley MA, Small CJ, et al. Gut hormone PYY (3-36) physiologically inhibits food intake. Nature 2002; 418: 650-4.

18. Polińska B, Matowicka-Karna J, Kemona H. Rola greliny w organizmie. Postep Hig Med Dosw 2011; 65: 1-7.

19. Di Marzo V, Goparaju SK, Wang L, et al. Leptin-regulated endocannabinoids are involved in maintaining food intake. Nature 2001; 410: 822-5.

20. Horvath TL. Endocannabinoids and the regulation of body fat: the smoke is clearing. J Clin Invest 2003; 112: 323-6.

21. Anamthathmakula P, Sahu M, Sahu A. Evidence suggesting phosphodiesterase-3B regulation of NPY/AgRP gene expression in mHypoE-46 hypothalamic neurons. Neurosci Lett 2015; 604: 113-8.

22. Könner AC, Klöckener T, Brüning JC. Control of energy homeostasis by insulin and leptin: targeting the arcuate nucleus and beyond. Physiol Behav 2009; 97: 632-8.

23. Kocełak P, Zahorska-Markiewicz B, Olszanecka-Glinianowicz M. Hormonalna regulacja przyjmowania pokarmu. Endokrynol Pol 2009; 60: 296-301.

24. Otto-Buczkowska E, Mazur-Dworzecka U, Dworzecki T. Rola amyliny w utrzymaniu homeostazy glukozy i perspektywy jej zastosowania w terapii cukrzycy. Przegl Lek 2008; 65: 135-9.

25. Ding X, Saxena N, Lin S, et al. Exendin-4, a glucagon-like protein-1 receptor agonist, reverses hepatic steatosis in ob/ob mice. Hepatology 2006; 43: 173-81.

26. Nylec M, Olszanecka-Glinianowicz M. Mało znane nowe ogniwa regulacji poboru pokarmu. Postep Hig Med Dosw 2010; 64: 291-5.

27. Lihn A, Pedersen S, Richelsen B. Adiponectin: action, regulation and association to insulin sensitivity. Obes Rev 2005; 6: 13-21. 
28. Klöting N, Kovacs P, Kern M, et al. Central vaspin administration acutely reduces food intake and has sustained blood glucose-lowering effects. Diabetologia 2011; 54: 1819-23.

29. Ziora K, Suwała A, Ziora-Jakutowicz K. Waspina - nowy hormon tkanki tłuszczowej. Endokrynol Ped 2012: 13: 59-66.

30. Szlachcic A, Surmiak M, Majka J, Brzozowski T. Nesfatin-1: a new hormone in the control of food intake and the mechanism of damage and protection of gastric muc osa. Prz Gastroenterol 2012; 7: 339-50.

Received: 2.09.2015

Accepted: 25.10.2015 